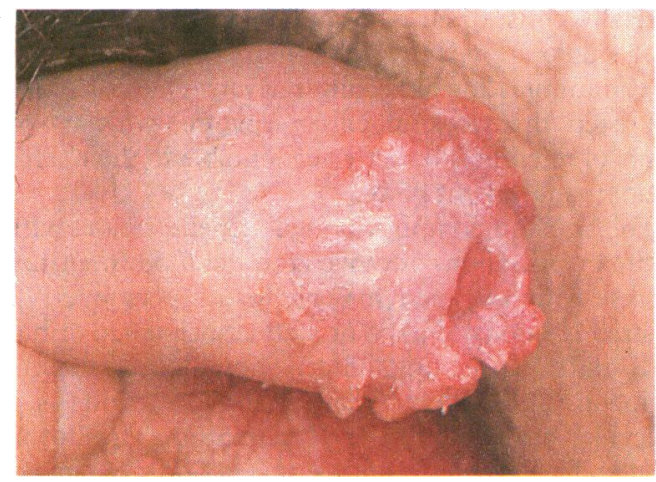

Genital warts. Secondary spread to the anal region is not uncommon.

\section{Treatment}

Several different methods of treatment have been described and should be adapted to the individual patient.

Repeated application of chemical agents such as podophyllin is suitable for small numbers of polyps outside the anal canal. Warts persisting after a month are unlikely to respond to further applications.

Persistent and more extensive warts are treated by surgical excision or ablation by diathermy. Infiltration of the affected area with a weak solution of adrenaline helps show the individual lesions, which can be picked off with a fine scalpel, preserving the intervening skin. Coagulation by using diathermy or laser is also effective but causes greater discomfort afterwards.

Recurrence is common so it is important to treat coexistent genital lesions and sexual partners. Advice about barrier contraception should be given where appropriate.

The photographs were produced by the department of medical illustration, Salford Health Authority, and the department of medical illustration, Manchester University.

$\mathrm{Mr} \mathrm{D} J$ Jones is lecturer and honorary senior registrar, department of surgery, and Dr B Goorney is consultant physician, department of genitourinary medicine, Hope Hospital, Salford.

The ABC of Colorectal Diseases has been edited by Mr D J Jones and Professor M H Irving, department of surgery, Hope Hospital, Salford.

\title{
How to implement a no smoking policy
}

\author{
Pamela Taylor
}

Implementing a no smoking policy at work is all about successfully managing change. The steps to follow look deceptively simple on paper-so bear in mind it is people (employees) we are talking about and the need to change people's attitudes and behaviour at work.

An increasing number of organisations are introducing workplace no smoking policies: some are pushed into it by their employees, some managements decide to initiate a policy, while others finally get around to rationalising a conflicting series of voluntary codes and obligatory regulations. In a major survey of employers almost $60 \%$ of respondents indicated smoking was their highest health promotion priority. ${ }^{1}$ Most organisations have some form of restrictions on smoking somewhere on their premises. Mainframe computers have had the right to breathe smoke free air for over 20 years, staff handling food have been used to grabbing a quick puff in the toilets rather than in the kitchens, and nobody expects to smoke around a toxic chemicals area.

In the United Kingdom the majority of the population do not smoke and many people choose to avoid exposure to environmental tobacco smoke. The workplace is one of the last remaining areas where many non-smokers still cannot avoid others' tobacco smoke. Pressure from employees has certainly played its part in encouraging management to introduce policies, but some employers have taken the initiative themselves, either in an attempt to enhance their corporate image or in an attempt to pre-empt any future legal requirements based on existing health and safety regulations, European Community regulation, and the law of negligence. The introduction of a well planned no smoking policy with careful consultation and presentation can be seen by employees as demonstrating management's commitment to the health, safety, and welfare of its staff. Managing organisational change well has its spin offs in improved internal communications and improved staff morale.

\section{Voluntary codes?}

It is pointless to raise the issue of smoking at work, risk antagonising employees, only to implement something which is clearly labelled "this code need not apply to you." Years of rows, arbitration, and management intervention await you based on continuing conflict and misunderstanding in the absence of a formal written policy. A voluntary code is no substitute for an agreed and properly implemented policy.

\section{Reasons for introducing a policy}

\section{HEALTH HAZARDS}

You will know of the health hazards associated with environmental tobacco smoke. Exposure causes eye irritation, headache, cough, sore throat, dizziness, and nausea. People with allergies and respiratory and heart ailments can also be seriously affected. Besides the acute effects of eye and throat irritation, exposure to tobacco smoke increases the risk of lung cancer and possibly of cardiovascular disease in non-smokers. As for the smokers themselves, about $81 \%$ of lung cancer deaths, $35 \%$ of all other cancers, and over $76 \%$ of cases of chronic bronchitis and emphysema are attributable to tobacco use, as are some $15-20 \%$ of deaths from coronary heart disease and stroke. The combined effect of smoking and occupational hazards shows there are significant differences in morbidity between smokers and non-smokers in many occupations and that the interaction of the two types of hazard increases the risk of many diseases. ${ }^{2}$

\section{THE LAW}

Environmental tobacco smoke is a health hazard. Employers have a duty to protect the health of employees, and employees have a duty to protect the health of their work colleagues. Smoking in the workplace is a health and safety issue, and employers are required by statute $\operatorname{law}^{3}(a)$ to protect their staff 


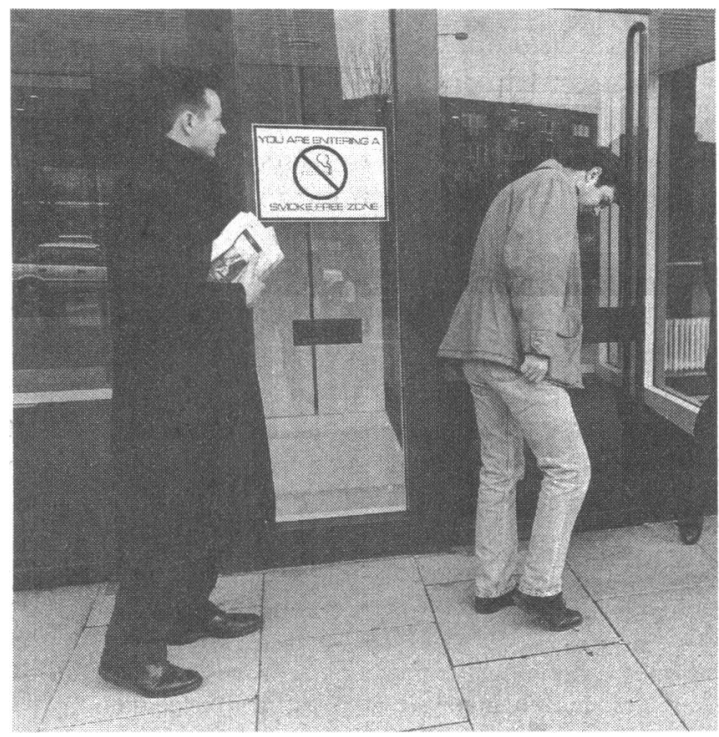

An increasing number of organisations are banning smoking in the workplace

from workplace hazards and $(b)$ to keep abreast of new information on health hazards and to act accordingly.

There is a point at which a court will rule that the employer should know of new information and act"the date of guilty knowledge." Some legal advisers believe we are at that stage now in view of the Froggatt report on the dangers of passive smoking. The repor states: "The health risks to non-smokers of environmental tobacco smoke provide added argument for the overall reduction of smoking in the community, and non-smoking should be regarded as the norm in enclosed areas frequented by the public or employees, special provision being made for smokers, rather than vice-versa."

Employers also have a common law duty to dea reasonably with matters of health or safety raised by their staff. So if you fail you could be sued for damages. A recent case saw an employee successfully claiming her asthma attacks were triggered by others' smoke. The social security commissioner ruled this was an industrial injury case.

A GOOD EMPLOYER

Perhaps the best reason for introducing a policy is the desire to be a good employer, demonstrating your commitment to the health of all employees. Many trade unions have established specialist health and safety departments to look after their members' interests at work. The organisation Industrial Relations Services reports that unions play an active part in the formulation and implementation of workplace policies, particularly in the public sector, working with management.

IMPROVE THE VENTILATION AND FORGET A POLICY?

Just in case you still harbour a secret desire to improve the ventilation system and forget the whole issue-it will not work. Both the particles and the gases in tobacco smoke contain irritants, toxins, and carcinogens. Some mechanical and electrical extractors can remove particles but they fail ${ }^{\circ}$ when it comes to the gases, which make up over $90 \%$ of the smoke.

\section{Taking it a step at a time}

ASH (Action on Smoking and Health) runs a full time advisory service to help companies introduce no smoking policies. It recommends five steps ${ }^{7}$ : (1) setting up a working party; (2) informing the workforce; (3) consulting the workforce; (4) working towards a policy; (5) implementing the policy.
1. NOT ANOTHER WORKING PARTY

Avoid the temptation to make do by extending the terms of reference of some existing working party. Smoking in the workplace is a big subject and it needs a specially constituted committee. By all means ensure your smoking policy working party has clear channels of communication with any relevant existing groups, but keep the working party separate, with its own terms of reference, directly accountable to the board or senior management body.

The size and composition will depend on the nature of the organisation, but give consideration to ensuring representation from management, personnel, industrial relations, unions or staff associations, or both, and staff representing office, shop floor, sales, and regional offices. You may wish to include some specialist health and safety, occupational health, and legal staff. Make sure both smokers and non-smokers are represented. Much time will be saved if the first meeting is used to ensure the objectives of the working group are clear. Make sure there is a written agenda and that agreed actions are written down.

The working party's role is crucial in striking the right balance between the gung-ho imposition of a policy and a talking shop which drags out the issue for months on end. An agreed outline timetable should be an aim for the first meeting together with agreed dates for future meetings.

\section{WILL A MEMO TO ALL STAFF DO?}

The success or failure of your endeavour will depend on the working party's ability to communicate well, thereby creating an atmosphere receptive to change. A memo to all staff can form part of your communications exercise, but it is not sufficient on its own.

Check the usual channels of staff communication and use them. Implementing a no smoking policy can often highlight poor employee communications in an organisation, so it may well be necessary to introduce some new ideas. You can consider health promotion programmes; it may be a good idea to distribute leaflets to all the staff on environmental tobacco smoke; posters can be displayed on notice boards; displays can be set up in canteens, sports areas, etc; articles can be written for in house newsletters; or you may wish to bring in an outside expert to hold a series of staff briefing meetings. Once you have opened up the channels of communication with the staff keep the information flowing. Make certain that your first efforts at communication with the staff include your aims to help smokers to quit. Most organisations set up special quit clinics during office hours and encourage their staff to attend. It is not unusual for these clinics to lead on to the provision of general stress control clinics for all staff.

\section{I'VE INFORMED THEM SO WHY CONSULT THEM?}

Informing staff of the health hazards of environmental tobacco smoke, employer and employee responsibilities on current legislation, and your wishes to implement a no smoking policy all come before consulting the workforce. Now you are in a position to consult staff - which also ensures you act within the law. Consultation is a two way process: resist any temptation to inform and then impose.

One of the most common methods of consultation is a staff questionnaire. A questionnaire helps gauge attitudes and encourages employees to think through the related issues. Some employers follow up questionnaires with one to one interviews, formal staff briefings, and follow up questionnaires, which go into greater detail. The questionnaires can include questions on employees' opinions on whether smoking should be allowed at work and whether it should be restricted according to place or time; employees' own smoking 
habits and whether they would like to quit; whether other people's tobacco smoke bothers non-smokers, and if so in what way.

Other methods of consultation can include workplace ballots on suggested policy options, group discussions, suggestion boxes, computerised notice boards-anything which the working party believes best suits the culture of the organisation.

\section{POLICY? WHAT POLICY?}

Even if everything has gone well until now, deciding on the nature of the final policy can be harrowing. Is non-smoking to be the norm, with smoking breaks in designated rooms? Will you introduce a comprehensive no smoking rule? The working party will need to gather all the relevant information to help reach a decision. What are the results of the workforce questionnaires? Is there an existing policy for some staff or areas? Where is smoking already banned to safeguard equipment or protect food? Could communal areas be a first step? Does practice vary from one site to another? Do you have to consider visitors or members? Are your offices mostly open plan? How are the smokers' quit clinics progressing? Bear in mind the key objectives agreed at the first working party meeting; remember the overriding need to protect non-smokers from tobacco smoke and to fulfil your obligations under health and safety legislation.

More and more organisations are opting for a comprehensive no smoking rule on all premises. Some organisations opt for an interim policy of incorporating smoking breaks in designated rooms, making it clear they will progress to a comprehensive no smoking rule after an agreed period. Others decide to review the

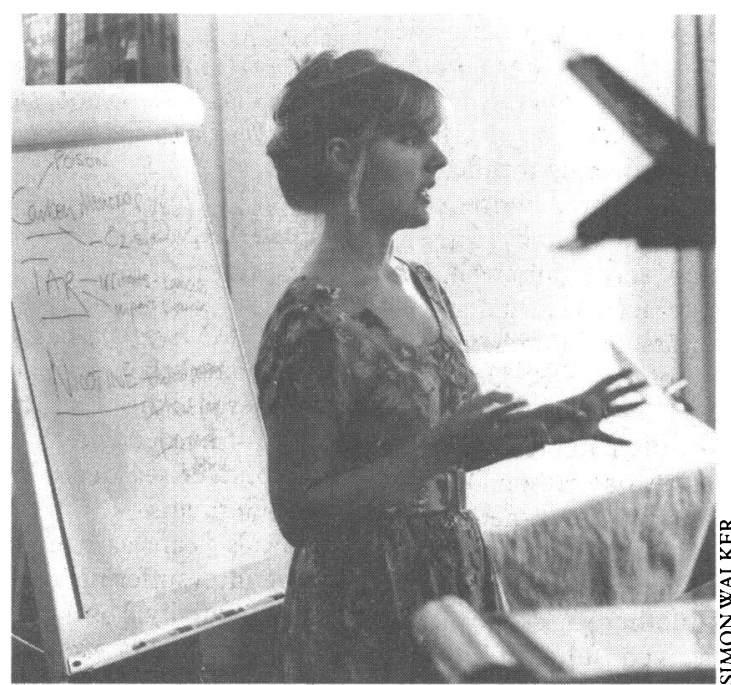

Most organisations set up quit smoking clinics, at which the hazards of environmental tabacco smoke are emphasised policy after an agreed period without prejudice to the outcome.

\section{READY FOR ACTION}

Before you go live make sure the key players are fully informed on the policy the working party is proposing. Senior managers, union officials, and others must be satisfied they understand the policy, they appreciate how it was arrived at, they know how it will be implemented and monitored, and they are agreed on rules for compliance.

A survey of 100 companies showed warning periods of implementation ranging from two weeks to 14 months; the most common notice period was three months. There is a statutory obligation to consult under section 49 of the Employment Protection (Consolidation) Act 1978 and to give reasonable notice of any changes in employees' terms and conditions of service. Once staff have been consulted and the policy agreed it is necessary to implement it. Let the staff know the details of the policy and use the notice period as a further opportunity to communicate.

You could:

- Update display materials on the effects of environmental tobacco smoke

- Produce a special staff newsletter and highlight the efforts of the staff who have managed to quit

- Commission specially designed posters and no smoking signs to fit in with the organisation's corporate identity

- Replace any cigarette vending machines

- Place stubbing bins at entrances to smoking and non-smoking areas.

You could call a final meeting of the working party and ensure the smooth handover to the personnel department. In particular, check responsibility for:

- Handling the problems created by changes of staff accommodation

- The monitoring of the policy

- Sorting out any initial problems with implementation

- Any non-compliance by staff

- Conditions and terms of employment

- Display materials and signs

- Progress with quit sessions for smokers

- Staff briefings

- Feedback on the running of the policy

- Monitoring the policy.

1 Smoking at work. I-Why and how employers introduce smoking policies. Industrial Relations Services Review and Report 1992 Feb: No 506.

2 World Health Organisation Programme on Tobacco or Health. Tobacco-free workplaces: safer and healthier. Geneva: WHO, 1992. (Advisory kit.)

3 Health and Safety at Work Act 1974. London: HMSO, 1974.

4 Independent and Scientific Committee on Smoking and Health. Fourth report. London: HMSO, 1988. (Chair: P Froggatt.)

5 Social Security Commissioner. Decision of the social security commissioner (re Joan Clay) appeal tribunal, 16 July 1990. Case No 2:11:1935.

6 United States Surgeon General. The health consequences of involuntary smoking. Rockville, Md: Department of Health and Human Services, 1986 7 Jenkins M. Smoking policies at work. London: Health Education Authority,
1987 .

\section{ANY QUESTIONS}

Do water tanks made of asbestos cement pose any risk to health?

There are two aspects to this question: the effect of drinking water that may contain asbestos fibres and the potential for the tank to release asbestos into the air.

Asbestos cement was used extensively in the manufacture of cold water storage tanks from about 25 years ago until it was superseded by plastic. These tanks are still commonly found. Constructed of a cement containing $10-15 \%$ asbestos (white or brown), they were specially treated to make them waterproof. Because of this they are hard wearing and do not tend to release asbestos fibres into the water. Furthermore, there is no evidence that ingestion of asbestos harms humans and there is good evidence that it does not hurt animals.'

Because of their relatively sheltered, undisturbed locations these tanks should not deteriorate for decades. Consequently, the risk of airborne release of asbestos fibres is remote. Activities that might generate asbestos dust, such as drilling and sawing, should be unnecessary as holes for plumbing were incorporated during manufacture.

If the tank must be removed it should be drained, disconnected, wrapped in plastic, and taken out in one piece for disposal at a licensed tip.-ALAN SCOTT, senior employment medical adviser, Health and Safety Executive, Nottingham

1 Parkes WR. Occupational lung disorders. London: Butterworth, 1982:286. 